\title{
BMJ Open Analysis of the management and costs of headache disorders in Spain during the period 2011-2016: a retrospective multicentre observational study
}

\author{
Josep Darbà (D) , ${ }^{1}$ Alicia Marsà ${ }^{2}$
}

To cite: Darbà J, Marsà A. Analysis of the management and costs of headache disorders in Spain during the period 2011-2016: a retrospective multicentre observational study. BMJ Open 2020;10:e034926. doi:10.1136/ bmjopen-2019-034926

- Prepublication history for this paper is available online. To view these files, please visit the journal online (http://dx.doi. org/10.1136/bmjopen-2019034926).

Received 11 October 2019 Revised 28 January 2020 Accepted 30 January 2020

A) Check for updates

(c) Author(s) (or their employer(s)) 2020. Re-use permitted under CC BY-NC. No commercial re-use. See rights and permissions. Published by BMJ.

${ }^{1}$ Department of Economics, Universitat de Barcelona, Barcelona, Spain

${ }^{2}$ Department of Health Economics, BCN Health Economics \& Outcomes Research SL, Barcelona, Spain

Correspondence to

Dr Josep Darbà; darba@ub.edu

\section{ABSTRACT}

Objectives To investigate the number and characteristics of the Spanish population affected by headache disorders and the direct medical cost that these patients represent for the healthcare system.

Design A retrospective multicentre observational study. Setting Records from all patients admitted with headache in primary and secondary care centres in Spain between 2011 and 2016 that were registered in a Spanish claims database were included in the analysis. Direct medical costs were calculated using the standardised average expenses of medical procedures determined by the Spanish Ministry of Health.

Results Data extraction claimed primary care records from 636722 patients and secondary care records from 30077 patients. Women represented $63 \%$ and $65 \%$ of all patients with headache in primary and secondary care respectively, with the exception of cluster headaches, a group with $60 \%$ of male patients. No large shifts were observed over time in patients' profile; contrarily, the number of cases per 10000 patients attended in primary care increased 2-folds between 2011 and 2016 for migraine and 1.85-folds for other headaches. Migraine was the cause for $28 \%$ of primary care consultations and $50 \%$ of secondary care admissions, and it was responsible for the largest portion of healthcare costs in 2016, a total amount of $€ 7302718$. The estimated annual direct medical cost of headache disorders was $€ 10716086$.

Conclusions Migraine was responsible for half of the secondary care admissions linked to headache disorders. The raise detected in the number of cases registered in primary care is likely to impact the direct medical costs associated to these disorders causing an increase in the total burden they represent for the Spanish National Healthcare System.

\section{INTRODUCTION}

Headache disorders are extremely common, experienced by practically everyone at some moment in their lives. Annually, the percentage of adult population affected with headache is around $50 \%$ when the multiple types of headache are considered. ${ }^{1}$ Primary headache disorders include migraine, tension-type headache (TTH), trigeminal autonomic cephalalgias (cluster headache

\section{Strengths and limitations of this study}

- The inclusion of primary and secondary care data allows a wider analysis of disease management.

- Patient records included all diagnoses registered upon admission, which permits a comorbidity analysis.

- The burden of prescription drugs could not be evaluated via this database.

and hemicrania continua) and others, including primary cough headache or those associated with sexual activity. ${ }^{2}$ The most common form is TTH, which affects around $38 \%$ of the population. ${ }^{3}$ Contrarily, trigeminal autonomic cephalalgias have a considerably low prevalence. For cluster headache it is less than $1 \%$, yet, it is of raising interest due to the severity of its symptoms and its impact in patients' lives. ${ }^{4}$

As for migraine, the estimated affected population remains around $10 \%$ globally, with a $12.6 \% 1$ year prevalence in $\operatorname{Spain}^{56}$; indeed, according to the Spanish Statistical Office, $5.1 \%$ of men and $13.6 \%$ of women were diagnosed with migraine or frequent headache in Spain in 2017. ${ }^{7}$ Migraine's socioeconomic and personal impacts determine its relevance, as it is considered a major cause of disability worldwide. ${ }^{8}$ The primary migraine classification entails migraine with aura or without aura; secondary classifications include chronic migraine, hemiplegic migraine and migraine of other origins.

Altogether, these disorders affect a large portion of the population, especially during working age, which implicates great public health repercussions and socioeconomic costs. ${ }^{9}$ Medical surveys across Europe have shown deficiencies in the care that patients with persistent headache and migraine receive; the portion of patients with migraine lacking medical treatment remains 
significant, and antimigraine treatments are used inadequately in an elevated percentage of cases. ${ }^{10}$ Such investigations highlight the need to improve health protocols for headache symptoms in an effort to reduce their personal and economic burden.

The availability of real-world evidence that reflects current practice is considered crucial for resource allocation decisions in public health and the revision of the established protocols and guidelines. ${ }^{11} 12$ Recent data examining the prevalence and characteristics of patients with headache and migraine are not available; additionally, previous statistics regarding the Spanish population were obtained via survey, with an assumed analytical error entailed. Hence, the interest on obtaining updated epidemiologic data regarding these conditions.

The aim of this study was to revise disease incidence and the profile of the Spanish population affected by headaches and migraine, contributing with novel data obtained from a Spanish claims database. A second objective was to evaluate the direct medical cost that these patients represent for the healthcare system, providing a basis for the optimisation of resource allocation decisions.

\section{METHODS}

\section{Data extraction}

Records of inpatient and outpatient admissions due to headache were extracted from a Spanish Ministry of Health database that compiles data from private and public hospitals, covering around $90 \%$ of admissions, and primary care centres, covering around $10 \%$ of the Spanish population, from all Spanish regions. ${ }^{1314}$ The 9 th and 10th revisions of the International Statistical Classification of Diseases and Related Health Problems, Clinical Modification (ICD9-CM and ICD10-CM) were used to claim all admissions registered with a principal diagnosis (admission motive) of headache, classified in accordance with The International Classification of Headache Disorders, 3rd edition (ICHD-3). Equally, four codes from The International Classification of Primary Care (ICPC) were used to claim primary care records, corresponding to migraine alone, TTH, cluster headache and unspecified headaches. Within the database, any healthcare visit that is registered in the system is considered an admission. Primary care admissions are inherently outpatient and specialised care inpatient and outpatient admissions are discernible by the length of stay parameter. The records extracted corresponded to admissions from the years 2011 to 2016, the last available data.

Parameters such as health centres and medical history identifiers were recoded prior to extraction to maintain records anonymised, with no access to identifying information, in accordance with the principles of Good Clinical Practice and the Declaration of Helsinki. In such cases the Spanish legislation does not require patient consent and ethics committee approval. ${ }^{15}$

\section{Patient and public involvement}

Patients were not directly involved in the design, planning and conception of this study.

\section{Data analysis}

The complete admission data was used for both primary care and hospitalisation records to evaluate patients' nature of admission and discharge, length of stay, services that treated the patients and medical procedures utilised. Repeated records corresponding to separated admissions were eliminated for the analysis of patients' characteristics, relying on the first admission as the index event. The direct medical cost was calculated based on the standardised average expenses of admissions and medical procedures determined by the Spanish Ministry of Health, available for the year 2016. Cost is presented in total cost of all registered admissions and average cost per hospitalised patient. These figures include all expenses related to the admission: treatment (examination, medication and surgery), nutrition, costs associated to personnel, medical equipment and resources. Data related to prescription medication was not available.

Data presentation is mainly descriptive. The number of cases per 10000 persons attended in primary care was calculated from the Ministry of Health database descriptive information. ${ }^{16}$ Two-sample $\mathrm{Z}$ tests were used to test for differences in sample proportions, with a $\mathrm{p}<0.05$ considered statistically significant. Statistical analyses were performed using Microsoft Excel Professional Plus 2010 (Microsoft Corporation, Redmond, Washington, USA) and StataSE V.12 for Windows (StataCorp LP. 2011. Stata Statistical Software: Release 12. College Station, Texas, USA).

\section{RESULTS}

\section{Patient profile}

Four unique ICPC codes were used to identify patients with unspecified headache, migraine, specified TTH and cluster headaches in primary care files, claiming 1829 571 records. For hospitalisation records, 97 ICD9 and IC10 codes were clustered in 16 sets that identified 32 517 admissions between 2011 and 2016. Once indexed by patients' first admission, 636722 single-patient primary care files and 30077 hospitalisation files remained.

The analysis of single-patient data revealed a significant sex bias, with a higher percentage of female patients in most cases, with the exception of cluster headache. In this last group, $61.67 \%$ of the patients attended in primary care and $59.14 \%$ of those attended in hospitals were men (table 1 ). The overall male/female ratio in primary care was $37.47 \%$ vs $62.53 \%$ while in secondary care it was 34.84 vs $65.15 \%$.

Patients' age displayed great variability, although the mean age for most patients with classifiable syndromes remained between 30 and 50 years. Mean patients' age in secondary care slightly increased during the study period. 
Table 1 Number $(\mathrm{N})$ and characteristics of patients diagnosed with headache disorders in primary and secondary care centres

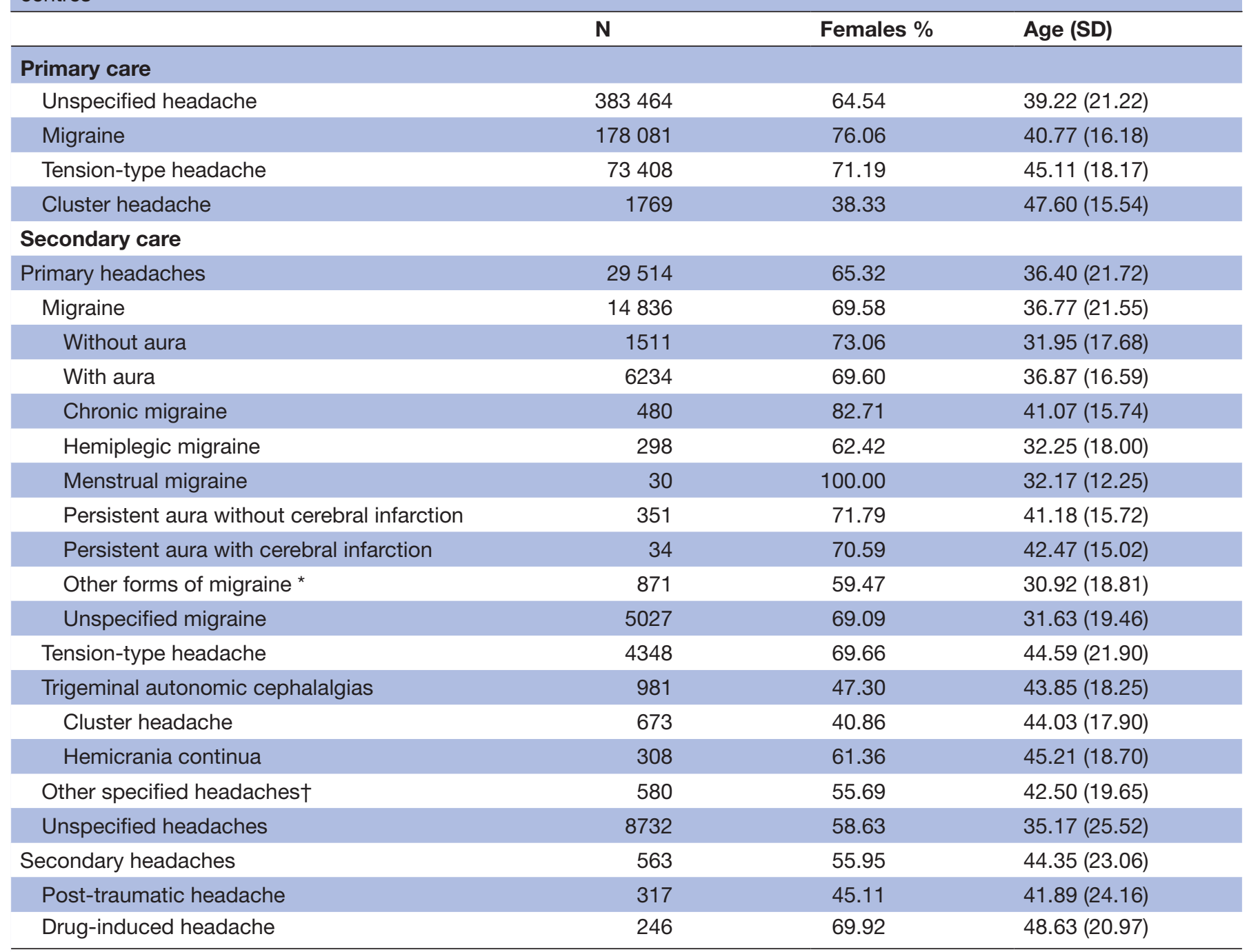

*With or without mention of status migrainosus.

†Hypnic, primary cough, exercise and stabbing headache, headache associated with sexual activity.

Primary care records allowed an analysis of patients' socioeconomic status. In all cases, around $60 \%$ of the patients had an income level below $€ 18000$, while in around $20 \%$ this ranged between $€ 18000$ and $€ 99999$. Patients' employment status displayed a more irregular distribution than patients' income, with a clear diminished percentage of pensioners $(13.82 \%)$. The active population represented $38.38 \%$ of total patients, while not active or unemployed patients summed $32.50 \%$ of the total.

On the other hand, hospital records included a register of secondary diagnoses, utilised for the evaluation of disease comorbidities, which were evaluated for migraine and other headache types separately. In addition, data corresponding to male and female patients was analysed independently (table 2). Overall, hypertension was the most common comorbidity, followed by disorders of lipoid metabolism as hypertriglyceridemia and hyperlipidaemia. Significant differences appeared between men and women in the diagnosis of mood disorders (anxiety, depressive disorder and dysthymic disorder) and hypothyroidism, primarily found in female patients. The frequency of essential hypertension, diabetes, dysthymic and depressive disorders and vomiting was consistently and significantly higher in patients with migraine vs those with other headaches.

The most common comorbidities displayed in table 2 were analysed in relation with age. Significant differences appeared among age groups. Hypertension was found in $28.34 \%$ of admissions in patients older than 36 years of age, while in those under 36 it was found in $1.51 \%$ of admissions $(p<0.001)$. The same effect was found for the disorders of lipoid metabolism, diabetes, hypothyroidism, dysthymic and depressive disorders, diagnosed in $16.56 \%$, $8.75 \%, 6.06 \%, 6.71 \%$ and $6.14 \%$ of admissions in older patients, respectively, and $0.81 \%, 0.24 \%, 1.50 \%, 147 \%$ and $0.85 \%$ of admissions in younger patients, respectively $(\mathrm{p}<0.001)$. 
Table 2 Secondary diagnoses found in patients with migraine and with other headache disorders (excluding migraine)

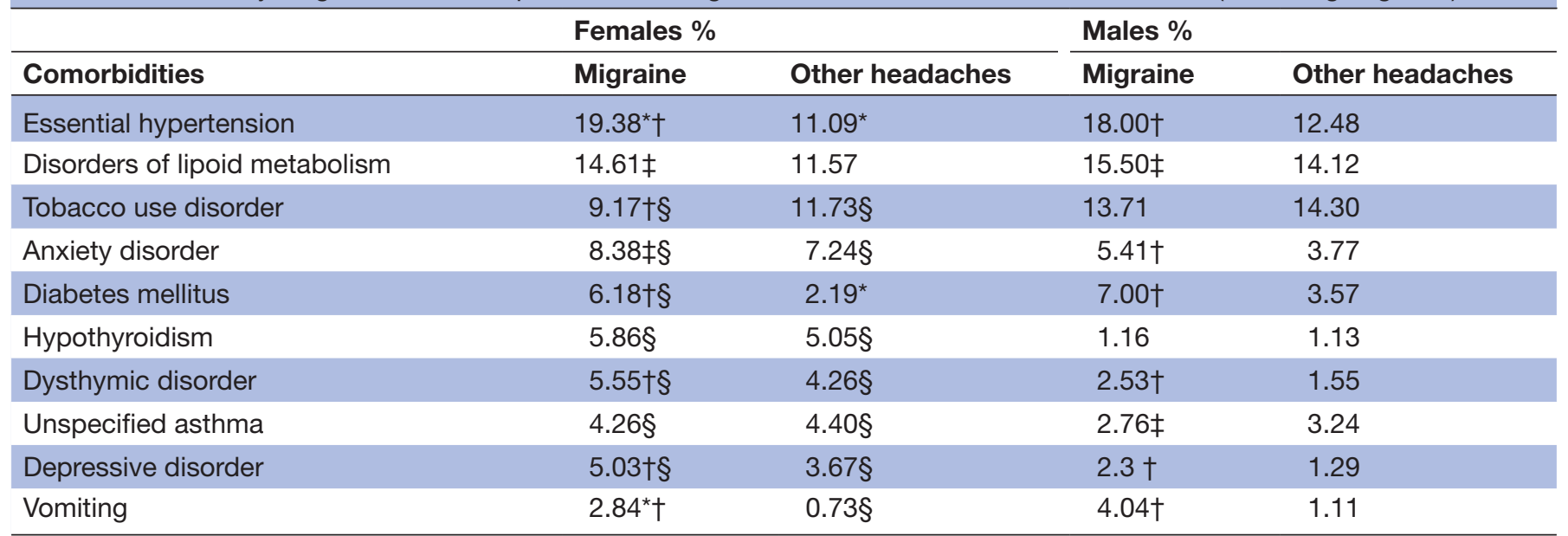

${ }^{*} \mathrm{p}<0.05$, women versus men.

$\dagger p<0.001$, migraine versus other headaches.

$\ddagger \mathrm{p}<0.05$, migraine versus other headaches.

$\S p<0.001$, women versus men.

\section{Healthcare management}

Total admission data was analysed to obtain information on patients' use of resources and management of the disease in both primary and secondary care. Persistent headache and migraine were controlled mostly in primary care facilities. It was in these centres where the highest number of admissions per patient was registered, an average of 2.8 for all headaches, 3.2 for migraine alone. One admission per patient was registered, on average, in specialised centres.

The number of primary care admissions linked to headache disorders in primary care augmented considerably over time. The year 2011, 89958 admissions were registered for all headache disorders, 26459 for migraine alone; in contrast, the year 2016 those were 451086 and 141 252, while the number of new patients remained stable. In addition, the number of cases per 10000 individuals attended in primary care was calculated, which included new patients and successive visits (figure 1). The number of cases per 10000 patients attended in

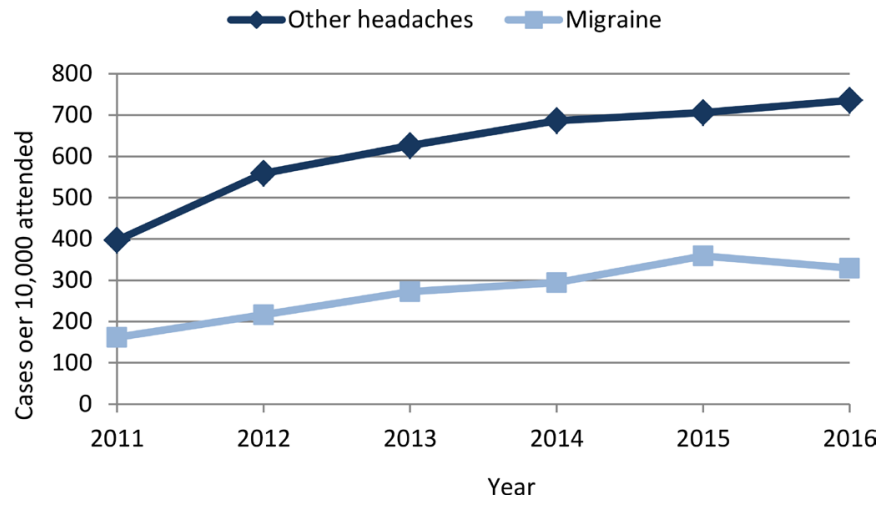

Figure 1 Annual number of cases of headache disorders and migraine alone registered per 10000 primary care admissions. primary care increased 2-folds between 2011 and 2016 for migraine and 1.85-folds for other headaches $(\mathrm{p}<0.001$, 2011 vs 2016).

In primary care, patients admitted with migraine represented $28.0 \%$ of the total, while in secondary care the proportion of patients with migraine was $49.7 \%$ (figure 2A). The scrutiny of specialised care data alone showed a predominance of migraine with aura, followed by patients with TTH (figure 2B).

The vast majority of hospital admissions for headache disorders $(90 \%)$ were due to emergencies and patients stayed hospitalised an average of 4.4 days. Posterior transfers to other facilities were not significant, with $98 \%$ of the patients discharged to their residences.

The service to treat the most patients was neurology $(51.85 \%)$, followed by paediatrics $(22.33 \%)$ and internal medicine $(16.53 \%)$. In all cases, procedures related to head and brain diagnostic imaging were predominant (table 3).

A)

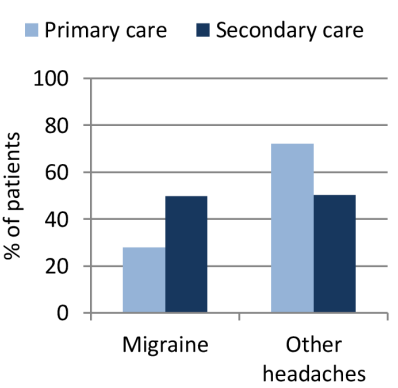

B)

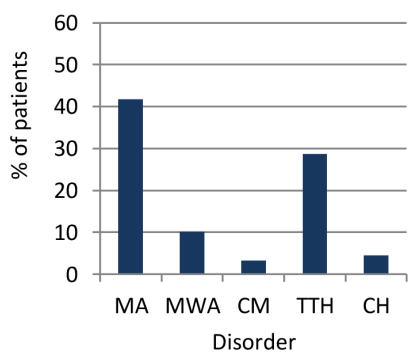

Figure 2 (A) Patients with migraine alone and other headaches in primary and secondary care. (B) Percentage of patients per headache type in secondary care. $\mathrm{CH}$, cluster headache; $\mathrm{CM}$, chronic migraine; MA, migraine with aura; MWA, migraine without aura; $\mathrm{TH}$, tension-type headache. 


\begin{tabular}{lc}
$\begin{array}{l}\text { Table } 3 \text { Medical procedures performed in more than } 5 \% \text { of } \\
\text { admissions }\end{array}$ \\
\hline $\begin{array}{l}\text { Procedures } \\
\text { admissions }\end{array}$ \\
\hline $\begin{array}{l}\text { Computerised axial tomography of head (CT } \\
\text { scan) }\end{array}$ & 41.86 \\
MRI of the brain & 34.11 \\
\hline $\begin{array}{l}\text { Injection or infusion of a therapeutic } \\
\text { substance }\end{array}$ & 11.26 \\
\hline Spinal tap & 11.07 \\
\hline Microscopic examination of blood & 10.49 \\
\hline Echoencephalography & 9.52 \\
\hline ECG & 9.40 \\
\hline Electroencephalography & 7.40 \\
\hline Routine chest X-ray & 6.37 \\
\hline Arteriography of cerebral arteries & 5.23 \\
\hline
\end{tabular}

\section{Direct medical cost}

The economic costs associated with patients' use of healthcare resources were evaluated for the year 2016 (table 4). This calculation comprises the cost of secondary healthcare associated with a hospitalisation event, and is determined by the mean cost of medical procedures and hospitalisation days. Headache disorders summed a total annual cost of $€ 10716086$. Migraine alone represented $€ 7302718$ of the total annual cost.

Finally, patients financing scheme was evaluated. As expected, the majority of patients were financed by the public health system $(95.65 \%)$.

\section{DISCUSSION}

\section{Patient profile}

According to the Spanish Statistical Office, around 9.4\% of the Spanish population annually suffers from migraine or another frequent headache. ${ }^{7}$ A national health survey reported similar numbers for the year 2017, and estimated that $5.1 \%$ men and $13.6 \%$ women were affected by this condition. ${ }^{17}$ In the same line are those found in the present study, with a male/female ratio of $37.47 \%$ to $62.53 \%$ and $34.84 \%$ to $65.15 \%$ in primary and secondary healthcare centres respectively. Equally, surveys have shown incidence rates that peak in patients between 35 and 45 years, which has been confirmed by healthcare records, ${ }^{17}$ with no large shifts observed over time in patients' age and sex distribution. ${ }^{18}$

The influence of patients' socioeconomic status was not determining in this study; while the majority of patients had an income level of under $€ 18000$, no direct links were found with their employment status.

Previous population-based studies have linked headaches to several comorbid conditions. Associations have been found with illnesses and disorders as hypertension, diabetes, hyperlipidaemia, asthma, obesity, hypothyroidism and depressive disorders. ${ }^{19-24}$ Small differences
Table 4 Direct medical costs associated to secondary care for the year 2016

\begin{tabular}{|c|c|c|}
\hline Headache disorders & $\begin{array}{l}\text { Cost per } \\
\text { patient }\end{array}$ & Total cost \\
\hline Primary headaches & $€ 2796$ & $€ 10445179$ \\
\hline Migraine & $€ 2736$ & $€ 7302718$ \\
\hline Without aura & $€ 2752$ & $€ 880585$ \\
\hline With aura & $€ 2674$ & $€ 3123802$ \\
\hline Chronic migraine & $€ 3132$ & $€ 219246$ \\
\hline Hemiplegic migraine & $€ 2903$ & $€ 142247$ \\
\hline Menstrual migraine & $€ 2019$ & $€ 8077$ \\
\hline $\begin{array}{l}\text { Persistent migraine aura } \\
\text { without cerebral infarction }\end{array}$ & $€ 2554$ & $€ 125144$ \\
\hline $\begin{array}{l}\text { Persistent migraine aura } \\
\text { with cerebral infarction }\end{array}$ & $€ 3843$ & $€ 30744$ \\
\hline Other forms of migraine* & $€ 2933$ & $€ 225836$ \\
\hline Unspecified & $€ 2757$ & $€ 2547038$ \\
\hline Tension-type headache & $€ 2803$ & $€ 1981425$ \\
\hline $\begin{array}{l}\text { Trigeminal autonomic } \\
\text { cephalalgias }\end{array}$ & $€ 3534$ & $€ 653752$ \\
\hline Cluster headache & $€ 3712$ & $€ 478789$ \\
\hline Hemicrania continua & $€ 3124$ & $€ 174963$ \\
\hline Other specified headaches $†$ & $€ 2941$ & $€ 405820$ \\
\hline Unspecified & $€ 2742$ & $€ 101464$ \\
\hline Secondary headaches & $€ 2913$ & $€ 270907$ \\
\hline Post-traumatic headache & $€ 2695$ & $€ 137452$ \\
\hline Drug-induced headache & $€ 3336$ & $€ 133455$ \\
\hline
\end{tabular}

*With or without mention of status migrainosus.

†Hypnic, primary cough, exercise and stabbing headache, headache associated with sexual activity.

were observed between male and female patients, principally in the diagnosis of mood disorders and hypothyroidism, which appeared to play a more significant role in women. These findings were in line with previous estimations in the general population. ${ }^{25}{ }^{26}$ Similarly, essential hypertension, diabetes, dysthymic and depressive disorders and vomiting were primarily diagnosed in patients with migraine versus other headaches. Age was another determinant factor in the diagnosis of comorbidities; older patients were more likely to be diagnosed with hypertension, disorders of lipoid metabolism, diabetes, hypothyroidism, dysthymic and depressive disorders, while the diagnosis of tobacco use disorder, anxiety disorder, asthma and vomiting symptoms did not display this correlation.

\section{Healthcare management}

Patients seeking medical attention for headache disorders in Spain were mostly handled in primary care centres. The number of patients registered in secondary care facilities was only $21 \%$ of the total patients registered in primary 
care, and referral to specialised care and emergency visits were in half of the cases due to migraine. Migraines with aura were predominant among patients receiving hospital inpatient and outpatient care, although aura has been found in only $30 \%$ of all patients with migraine. ${ }^{27}$

The prevalence of migraine was estimated to increase from $6.5 \%$ in 2003 to $9.7 \%$ in $2012 .{ }^{28}$ Herein, primary care data inclusion increased a $70 \%$ during the study period, which explains the increase registered in the number of admissions. ${ }^{16}$ Nonetheless, the number of cases per 10 000 patients attended in primary care increased significantly over the study period, including new patients and successive visits. Additionally, previous evaluations suggest that neurology consultations, predominant in this study, are mainly related to ineffective treatment or increased frequency of migraine attacks, which could indicate the need to improve treatment protocols. ${ }^{29}$

Regarding the management of these disorders at the hospital level, recommendations call to avoid imaging for uncomplicated headache, while previous analysis revealed a tendency to perform unnecessary neuroimaging tests in patients that fall into that category. ${ }^{30}{ }^{31} \mathrm{~A}$ study developed in 2014 in the north of Spain investigated the possible overuse of neuroimaging procedures in patients with chronic migraine in a headache clinic. ${ }^{32}$ The number of tests performed was considered adequate, but CT scans were registered in $76 \%$ of admissions and MRI in $42 \% .^{32}$ Further research will be necessary to determine the current application of such recommendations in Spain.

\section{Direct medical cost}

Updated real-world evidence plays a pivotal role in resource allocation decisions in public health. ${ }^{11} 12$ Hence, it appears crucial to measure not only patients' use of healthcare resources but the direct medical cost associated.

Altogether, headache disorders represent great personal and socioeconomic costs, though most evaluations have its focus on migraine. Migraine was identified as the sixth leading cause of disability-adjusted life years worldwide in people between 25 and 39 years in 2015, and those suffering from it are known to have a significantly lower health-related quality of life, increased work impairment and to require a more intensive healthcare resource utilisation. ${ }^{33} 34$ To quantify the costs of this increased use of medical resources, previous studies used disease prevalence data as a primary approach. In this way, the direct cost of migraine in Spain was estimated to sum $€ 344$ million in 2004, including medical admissions and prescription medicine. ${ }^{35}$ Posterior evaluations based on surveys measured costs per patient of $€ 1092$ to treat episodic migraine in 2012, $€ 920$ when excluding medication costs, ${ }^{36}$ a cost significantly lower to that obtained in this study, where the costs of specialised admissions alone averaged $€ 2800$ per patient in 2016 . This cost is tightly associated with the number and nature of diagnostic tests; however, further research will be necessary to determine its utility and whether its use should be adjusted. In addition, the distinct calculation methods used in both studies cannot be ruled out as the origin of cost fluctuation.

This study found similar costs to treat the distinct headache disorders. Earlier calculations assumed a much lower annual cost of TTH, around $€ 300$ per person in $2011 .^{37}$ In the same revision, the estimated total burden of headaches in Spain was over $€ 22$ billion, including healthcare, medication costs and indirect costs (lost productivity). Herein, secondary care alone summed $€$ 10716086 . To add to this calculation is the burden linked to work productivity lost, a presumably significant sum, and medication.

A number of limitations may have influenced the results of this study. Direct medical costs were registered leaving out the expenses related to prescription medication, which need to be considered independently. Further research will be necessary to confirm the increasing tendency in medical costs and, as a consequence, the increasing burden derived from headache disorders.

\section{CONCLUSIONS}

Patients receiving specialised care represented around $21 \%$ of those treated in primary care, and as much as $28 \%$ of primary care consultations were due to migraine. In addition, this study shows the great importance of migraine in secondary care. The increasing number of cases of headache disorders attended in primary care centres is likely to provoke a raise in the direct medical costs associated, increasing the burden they represent for the Spanish National Healthcare System.

Contributors JD contributed to the investigation by analysing and interpreting the economic situation of headache disorders in Spain and was a major contribution in the intellectual content revision. AM analysed patient descriptive and disease management data over the study period and was a major contributor in writing the manuscript. All authors read and approved the final manuscript.

Funding The authors have not declared a specific grant for this research from any funding agency in the public, commercial or not-for-profit sectors.

Competing interests None declared.

Patient consent for publication Not required.

Ethics approval Parameters such as health centres and medical history identifiers were recoded prior to extraction to maintain records anonymised, with no access to identifying information, in accordance with the principles of Good Clinical Practice and the Declaration of Helsinki. In such cases the Spanish legislation does not require patient consent and ethics committee approval (Law 14/2007, 3 July, on biomedical research, Spain).

Provenance and peer review Not commissioned; externally peer reviewed.

Data availability statement Data may be obtained from a third party and are not publicly available. The data that support the findings of this study is available from the Spanish Ministry of Health via the Unit of Health Care Information and Statistics (Spanish Institute of Health Information) for researchers who meet the criteria for access to confidential data athttps://www.mscbs.gob.es/estadEstudios/ sanidadDatos/home.htm.

Open access This is an open access article distributed in accordance with the Creative Commons Attribution Non Commercial (CC BY-NC 4.0) license, which permits others to distribute, remix, adapt, build upon this work non-commercially, and license their derivative works on different terms, provided the original work is properly cited, appropriate credit is given, any changes made indicated, and the use is non-commercial. See: http://creativecommons.org/licenses/by-nc/4.0/. 
ORCID iD

Josep Darbà http://orcid.org/0000-0003-2371-0999

\section{REFERENCES}

1 Jensen R, Stovner LJ. Epidemiology and comorbidity of headache. Lancet Neurol 2008;7:354-61.

2 The International Headache Society. The International classification of headache disorders, third edition (ICHD-3). Available: https://www. ichd-3.org/ [Accessed May 2019].

3 Stovner LJ, Andree C. Prevalence of headache in Europe: a review for the Eurolight project. J Headache Pain 2010;11:289-99.

4 Fischera M, Marziniak M, Gralow I, et al. The incidence and prevalence of cluster headache: a meta-analysis of population-based studies. Cephalalgia 2008;28:614-8.

5 Matías-Guiu J, Porta-Etessam J, Mateos V, et al. One-year prevalence of migraine in Spain: a nationwide population-based survey. Cephalalgia 2011;31:463-70.

6 Roy R, Sánchez-Rodríguez E, Galán S, et al. Factors associated with migraine in the general population of Spain: results from the European health survey 2014. Pain Med 2019;20:555-63.

7 Office SS. Chronic conditions diagnosed by a doctor per sex, 2017. [Instituto Nacional de Estadística (INE). Principales enfermedades crónicas o de larga evolución diagnosticadas por un médico por sexo 2017 https://www.ine.es/jaxi/Datos.htm?path=/t00/mujeres hombres/tablas_1/I0/\&file=d03005.px (Accessed May, 2019).

8 Steiner TJ, Stovner LJ, Vos T, et al. Migraine is first cause of disability in under 50S: will health politicians now take notice? J Headache Pain 2018;19:17.

9 Steiner TJ, Stovner LJ, Katsarava Z, et al. The impact of headache in Europe: principal results of the Eurolight project. $J$ Headache Pain 2014;15:31.

10 Katsarava Z, Mania M, Lampl C, et al. Poor medical care for people with migraine in Europe - evidence from the Eurolight study. $J$ Headache Pain 2018;19:10.

11 Katkade VB, Sanders KN, Zou KH. Real world data: an opportunity to supplement existing evidence for the use of long-established medicines in health care decision making. $J$ Multidiscip Healthc 2018;11:295-304.

12 Justo N, Espinoza MA, Ratto B, et al. Real-World evidence in healthcare decision making: global trends and case studies from Latin America. Value Health 2019;22:739-49.

13 Ministry of Health, Social Services and Equality. Hospitalization report - CMBD - Discharge register: Report summary 2013 [Informe de hospitalización - CMBD - Registro de altas: Informe resumen 2013]. Madrid: Ministry of Health, Social Services and Equality, 2015.

14 Ministry of Health, Social Services and Equality. Primary Care clinical database. Data 2012. [Base de Datos Clínicos de Atención Primaria. Datos 2012. Madrid: Ministry of Health, Social Services and Equality, 2016.

15 Anon. [Law 14/2007, 3 July, on biomedical research (BOE, 4 July 2007)]. Rev Derecho Genoma Hum 2007:283-325.

16 Spanish Ministry of Health. Unit of health care information and statistics. Available: https://www.mscbs.gob.es/en/estadEstudios/ estadisticas/cmbdAnteriores.htm [Accessed Jan 2020].

17 Spanish Ministry of Health, Consumer Affairs and Social Welfare. National health survey. [Encuesta nacional de salud]. Madrid, 2017.

18 Fernández-de-Las-Peñas C, Hernández-Barrera V, Carrasco-Garrido $\mathrm{P}$, et al. Population-based study of migraine in Spanish adults: relation to socio-demographic factors, lifestyle and co-morbidity with other conditions. J Headache Pain 2010;11:97-104.

19 Aamodt AH, Stovner LJ, Midthjell K, et al. Headache prevalence related to diabetes mellitus. The Head-HUNT study. Eur J Neurol 2007;14:738-44

20 Peng $\mathrm{Y}-\mathrm{H}$, Chen K-F, Kao C-H, et al. Risk of migraine in patients with asthma: a nationwide cohort study. Medicine 2016;95:e2911.

21 Ornello R, Ripa P, Pistoia F, et al. Migraine and body mass index categories: a systematic review and meta-analysis of observational studies. J Headache Pain 2015;16:27.

22 Farello G, Ferrara P, Antenucci A, et al. The link between obesity and migraine in childhood: a systematic review. Ital J Pediatr 2017;43:27.

23 Tepper DE, Tepper SJ, Sheftell FD, et al. Headache attributed to hypothyroidism. Curr Pain Headache Rep 2007;11:304-9.

24 Yang Y, Ligthart L, Terwindt GM, et al. Genetic epidemiology of migraine and depression. Cephalalgia 2016;36:679-91.

25 Labaka A, Goñi-Balentziaga O, Lebeña A, et al. Biological sex differences in depression: a systematic review. Biol Res Nurs 2018;20:383-92.

26 Garmendia Madariaga A, Santos Palacios S, Guillén-Grima F, et al. The incidence and prevalence of thyroid dysfunction in Europe: a meta-analysis. J Clin Endocrinol Metab 2014;99:923-31.

27 Viana M, Afridi S. Migraine with prolonged aura: phenotype and treatment. Naunyn Schmiedebergs Arch Pharmacol 2018;391:1-7.

28 Fernández-de-las-Peñas C, Palacios-Ceña D, Salom-Moreno J, et al. Has the prevalence of migraine changed over the last decade (2003-2012)? A Spanish population-based survey. PLoS One 2014:9:e110530.

29 Mateos V, Porta-Etessam J, Armengol-Bertolin S, et al. [Initial situation and approach to the care of migraine in neurology services in Spain: the PRIMERA study]. Rev Neurol 2012;55:577-84.

30 Bailey JE, Wan JY, Mabry LM, et al. Does health information exchange reduce unnecessary neuroimaging and improve quality of headache care in the emergency department? J Gen Intern Med 2013;28:176-83.

31 Rosenberg A, Agiro A, Gottlieb M, et al. Early trends among seven recommendations from the choosing wisely campaign. JAMA Intern Med 2015;175:1913-20.

32 Martínez-Ramos J, Santamarta-Liébana E, Saiz-Ayala A, et al. [ls there overuse of neuroimaging procedures in patients with chronic migraine? An study in a Health Area in Asturias, Spain]. Rev Neurol 2014;59:205-8.

33 GBD 2015 DALYs and HALE Collaborators. Global, regional, and national disability-adjusted life-years (DALYs) for 315 diseases and injuries and healthy life expectancy (HALE), 1990-2015: a systematic analysis for the global burden of disease study 2015. Lancet 2016;388:1603-58.

34 Vo P, Fang J, Bilitou A, et al. Patients' perspective on the burden of migraine in Europe: a cross-sectional analysis of survey data in France, Germany, Italy, Spain, and the United Kingdom. $J$ Headache Pain 2018;19:82.

35 Badia X, Magaz S, Gutiérrez L, et al. The burden of migraine in Spain: beyond direct costs. Pharmacoeconomics 2004;22:591-603.

36 Bloudek LM, Stokes M, Buse DC, et al. Cost of healthcare for patients with migraine in five European countries: results from the International burden of migraine study (IBMS). $J$ Headache Pain 2012;13:361-78.

37 Linde M, Gustavsson A, Stovner LJ, et al. The cost of headache disorders in Europe: the Eurolight project. Eur J Neurol 2012;19:703-11. 